\title{
pesquisa
}

ABREU, I.N.; PINTO, J.E.B.P.; FURTINI NETO, A.E.; BERTOLUCCI, S.K.V.; LADEIRA, A.; GEROMEL, C. Nitrogênio e fósforo na produção vegetal e na indução de mucilagem em plantas de insulina. Horticultura Brasileira, Brasília, v. 20, n. 4, p. 536-540, dezembro 2002.

\section{Nitrogênio e fósforo na produção vegetal e na indução de mucilagem em plantas de insulina}

\author{
Ilka Nacif Abreu ${ }^{1}$; José Eduardo B. P. Pinto후; Antônio Eduardo Furtini Neto²; Suzan Kelly V. Bertolucci'; \\ Ângela Ladeira ${ }^{3}$; Clara Geromel ${ }^{1}$ \\ ${ }^{1}$ UFLA - Dept ${ }^{\circ}$ Agricultura; ${ }^{2}$ UFLA - Dept ${ }^{\circ}$ Ciências dos Solos, C. Postal 37, 37.200-000 Lavras-MG, ${ }^{3}$ Unicamp - Dept ${ }^{\circ}$ Fisiologia \\ Vegetal, 13.083-970 Campinas-SP; E-mail: jeduardo@ufla.br
}

\section{RESUMO}

Foi verificada a influência da adubação com nitrogênio e fósforo na produção de biomassa e de mucilagem em plantas de Cissus sicyoides. Plantas com 45 dias, formadas pelo método de estaquia, foram plantadas em vasos com capacidade para $5 \mathrm{~kg}$ de solo, contendo como substrato um Cambissolo álico, textura média, do município de Nazareno-MG. Foi realizada uma adubação básica com macro e micronutrientes, variando apenas as concentrações de nitrogênio e fósforo. $\mathrm{O}$ experimento consistiu de 5 doses de $\mathrm{N}(0 ; 40$; $80 ; 160$ e $200 \mathrm{mg}$ de $\mathrm{N} / \mathrm{kg}$ de solo) e duas doses de $\mathrm{P}$ (50 e $150 \mathrm{mg}$ de $\mathrm{P} / \mathrm{kg}$ de solo), com 4 repetições. $\mathrm{O}$ delineamento foi inteiramente casualizado, em esquema fatorial de $5 \times 2$. O experimento foi conduzido em casa de vegetação por 90 dias, onde avaliou-se o peso de matéria seca de folha, caule e raiz; características químicas e mucilagem da parte aérea. Houve interação entre as concentrações de nitrogênio e fósforo para a produção de matéria seca foliar, sendo que os maiores ganhos de biomassa ocorreram nas maiores doses de $\mathrm{N}$ com $150 \mathrm{mg}$ de $\mathrm{P} / \mathrm{kg}$ solo. A produção de mucilagem respondeu positivamente ao aumento das concentrações de nitrogênio e fósforo, atingindo o maior conteúdo nas mesmas concentrações que proporcionaram o maior ganho de biomassa foliar e de parte aérea total.

Palavras-chave: Cissus sicyoides, Vitaceae, planta medicinal, adubação química, polissacarídeos ácidos.

\begin{abstract}
Influence of nitrogen and phosphorus in the biomass production and induction of mucilage in "insulina" plants

The influence of nitrogen and phosphorus fertilization on production of biomass and mucilage in Cissus sicyoides plants was evaluated. 45-day old plants obtained from cuttings were planted in pots with capacity for $5 \mathrm{Kg}$ of soil, having as substrate allic cambisol soil, medium texture from Nazareno (Brazil). Basic fertilization with macro and micronutrients was done. Nitrogen doses $(0 ; 40 ; 80 ; 160$ and $200 \mathrm{mg}$ of $\mathrm{N} / \mathrm{Kg}$ of soil) and phosphorus doses (50 and $150 \mathrm{mg}$ of $\mathrm{P} / \mathrm{Kg}$ of soil) were evaluated. The experiment was laid out in a complete randomised factorial scheme of $5 \times 2$, with four replications. The research was carried out in a greenhouse during 90 days, being evaluated the dry matter of leaves, stalks and roots; chemicals characteristics and mucilage were determined. Between nitrogen and phosphorus doses and the production of dry matter of leaves was observed interaction. Higher biomass gain occurred with higher nitrogen dose of $150 \mathrm{mg} \mathrm{P} / \mathrm{Kg}$ of soil. The mucilage production increased with increasing doses of nitrogen and phosphorus, reaching a higher content at the same conditions that gave a higher leaves biomass gain and total aerial part.
\end{abstract}

Keywords: Cissus sicyoides, Vitaceae, medicinal plant, chemical fertilization, acids polysaccharides.

\section{(Recebido para publicação em 05 de outubro de 1999 e aceito em 10 de outubro de 2002)}

$C^{-}$ issus sicyoides, também conhecida como insulina vegetal, cipó-pucá e anil trepador, é trepadeira da América Tropical pertencente à família Vitaceae e encontrada na Região Amazônica. Esta espécie é usada popularmente no tratamento de diabetes, controle de estados epilépticos, sudorífico, hipotensor e no tratamento de doenças do coração (Albuquerque, 1989; Costa, 1990; Silva, 1995;). Dos seus frutos podem ainda ser extraídos pigmentos utilizados como corantes alimentícios (Toledo, 1983).

Esta espécie contém alcalóides, flavonóides (Moura, 1986; Albuquerque, 1989), esteróides, saponinas, compostos fenólicos, mucilagem (Silva,1995) e antocianinas (Toledo,1983) e tem atividade farmacológica comprovada no tratamento de convulsão, doenças do coração (Elisabetsky, 1988; Moura 1986; Costa, 1990) e controle de diabetes crônica (Pepato et al., 1998).

As mucilagens, que possuem atividade medicinal, são polissacarídeos complexos constituídos por unidades de açúcares e ácido urônico (Costa, 1978). Essas substâncias são produtos do metabolismo primário e geralmente se formam a partir da membrana celular ou se depositam sobre esta, formando camadas sucessivas (Silva, 1995). Sabese que as gomas de plantas são sais neutros de polissacarídeos ácidos comple- xos. Atribui-se às mucilagens a capacidade de atuar como substâncias de reserva e como as principais substâncias de armazenamento de água (Sierakowski, 1982). Além das funções citadas, as mucilagens apresentam, em diversas espécies, propriedades anti-inflamatórias, laxativas, anti-diarréicas e anti-diabéticas (Tomoda et al., 1987), entre outras. Na indústria alimentícia é utilizada na confecção de geléias e doces diversos e, na indústria farmacêutica, para correção do gosto de outros fármacos, estabilidade de emulsão e pomadas (Clemente Filha, 1996).

Os metabólitos produzidos a partir do metabolismo primário e secundário das plantas medicinais podem ser afe- 
tados pelas condições ambientais a que estão submetidas como fertilidade do solo, $\mathrm{pH}$, umidade, temperatura, qualidade da luz, dentre outros fatores (Becker, 1997).

Os nutrientes minerais podem influenciar no crescimento das plantas indiretamente, via seus efeitos no suprimento de assimilados e de substâncias de crescimento (Robson \& Pitmann, 1983). A influência dos nutrientes na fotossíntese pode ocorrer em várias vias, como por exemplo, o envolvimento direto do fósforo na cadeia de transporte de elétrons, nos tilacóides. Já o nitrogênio pode ser utilizado na formação dos cloroplastos, síntese protéica e síntese de clorofila (Moorby \& Besford, 1983). O fósforo está presente nas plantas, principalmente na forma de ortofosfato, sendo que a sua principal função é na tradução de energia. Durante o fluxo de elétrons na cadeia de transporte de elétrons, da mitocôndria e cloroplasto, a energia livre é associada com a oxidação dos componentes da cadeia, sendo convertida na forma de ATP (Glass, 1989). Desta maneira, nitrogênio e fósforo são necessários para que ocorra a síntese protéica e a ativação de uma série de enzimas e, consequentemente, a produção de biomassa vegetal (Marschner, 1995).

São raros, na literatura, trabalhos sobre a adubação de Cissus sicyoides e sua correlação com a síntese de mucilagem. Por isso o objetivo, do presente trabalho, foi verificar a influência da adubação na produção vegetal e de mucilagem, nesta espécie.

\section{MATERIAL E MÉTODOS}

Foi utilizado um solo proveniente do município de Nazareno (MG), classificado como Cambissolo álico, textura média. A análise química do solo, realizada antes e depois da aplicação dos tratamentos, seguiu a metodologia de Vettori (1969) com modificações de EMBRAPA (1979) e Camargo et al. (1986). Posteriormente, o substrato foi colocado em vasos com capacidade para $5 \mathrm{~kg}$ de solo, sem furos na sua base. Foi realizada a calagem, com o intuito de elevar o $\mathrm{pH}$ do solo para 6,0, onde adicionou-se as fontes $\mathrm{CaCO}_{3}$ e $\mathrm{MgCO}_{3}$ na proporção de 4:1, na forma de sais P.A., sendo as quantidades definidas pela curva de incubação.

A fertilização básica de cada tratamento consistiu de $150 \mathrm{mg} \mathrm{K} ; 45 \mathrm{mg} \mathrm{S}$; 1,5 mg Cu; 2,0 mg Fe; 5,0 mg Zn; 3,6 $\mathrm{mg} \mathrm{Mn;} \mathrm{0,8} \mathrm{mg} \mathrm{B;} \mathrm{0,15} \mathrm{mg} \mathrm{Mo} \mathrm{por} \mathrm{kg}$ de solo. As doses de P de 50 e $150 \mathrm{mg} /$ $\mathrm{Kg}$ de solo foram aplicadas junto com a adubação básica, de acordo com os tratamentos estudados. A adubação nitrogenada foi realizada, quinzenalmente, sendo que o número de aplicações variou de acordo com cada tratamento. A primeira aplicação (40 mg N/ $\mathrm{kg}$ de solo) foi realizada junto com a adubação básica em todos os tratamentos, com exceção dos controles. Os nutrientes foram aplicados em cada vaso na forma de soluções preparadas a partir de sais P.A., utilizando-se as seguintes fontes: $\mathrm{K}_{2} \mathrm{SO}_{4} ; \mathrm{KH}_{2} \mathrm{PO}_{4} ; \mathrm{H}_{3} \mathrm{PO}_{4}$; $\mathrm{H}_{3} \mathrm{BO}_{3} ; \mathrm{MnSO}_{4} . \mathrm{H}_{2} \mathrm{O} ; \mathrm{ZnSO}_{4} .7 \mathrm{H}_{2} \mathrm{O}$; $\mathrm{CuSO}_{4} \cdot 5 \mathrm{H}_{2} \mathrm{O} ;\left(\mathrm{NH}_{4}\right)_{6} \cdot \mathrm{Mo}_{7} \cdot \mathrm{O}_{24} \cdot 4 \mathrm{H}_{2} \mathrm{O}$; Fe-EDTA e $\mathrm{NH}_{4} \mathrm{NO}_{3}$. Após a correção do solo e aplicação dos tratamentos, os mesmos foram incubados por 15 dias, e a umidade foi mantida próxima da capacidade de campo.

As mudas foram preparadas com estacas contendo duas gemas, com aproximadamente $20 \mathrm{~cm}$, obtidas de plantas matrizes, oriundas do Instituto de Botânica do Estado de São Paulo. Estas foram colocadas para enraizar em sacos plásticos de polietileno contendo areia lavada como substrato e permaneceram nestas condições por 45 dias. Em cada vaso foram plantadas duas mudas.

$\mathrm{O}$ delineamento foi inteiramente casualizado, em quatro repetições, arranjado num fatorial de $5 \times 2$, sendo 5 doses de N (0; 40; 80; 160 e $200 \mathrm{mg} \mathrm{N} /$ $\mathrm{kg}$ de solo) e 2 doses de P (50 e $150 \mathrm{mg}$ $\mathrm{P} / \mathrm{kg}$ de solo).

A duração do experimento foi de 90 dias. Foram avaliados o peso da matéria seca de folha; teores e conteúdos de $\mathrm{N}, \mathrm{P}, \mathrm{K}, \mathrm{Ca}, \mathrm{Mg}, \mathrm{S}$ na matéria seca folha e quantidade de mucilagem na parte aérea.

A mucilagem foi extraída conforme metodologia descrita por Sierakowski (1982), com algumas modificações. O preparo do pó acetônico foi feito com porções de $100 \mathrm{~g}$ da parte aérea das plantas que foram primeiramente mergulha- das em etanol por 72 horas, secas ao ar e em seguida submersas em acetona por 48 horas, com posterior exposição ao ar, para secagem. A seguir, o material foi triturado em moinho tipo Willey, utilizando-se peneira de 60 mesh. O pó acetônico obtido foi submetido ao processo de extração em aparelho tipo Soxhlet, utilizando-se uma mistura de benzeno:etanol $(2: 1 \mathrm{v} / \mathrm{v})$, por 48 horas. $\mathrm{O}$ extrato resultante foi descartado.

Para a extração da mucilagem, o pó residual do tratamento com benzeno:etanol foi submetido ao processo de extração com água $(100 \mathrm{ml}$ de água $/ 5 \mathrm{~g}$ de amostra) a $85^{\circ} \mathrm{C}$, com agitação, durante 24 horas e o sobrenadante viscoso foi isolado por centrifugação. $\mathrm{O}$ resíduo foi novamente submetido a duas extrações, como anteriormente descrito, e os sobrenadantes foram reunidos. Em seguida, adicionou-se etanol (3 volumes) para a obtenção de um precipitado (após 24 horas), o qual foi separado por centrifugação (10.000 g/40 min) e o sobrenadante etanólico descartado. O precipitado contendo o polissacarídeo foi lavado com acetona (3 vezes) e seco a vácuo. $\mathrm{Na}$ seqüência, realizou-se a pesagem do polissacarídeo seco. Os dados e características avaliados foram submetidos ao Sistema de Análise de Variância.

\section{RESULTADOS E DISCUSSÃO}

\section{Efeito do nitrogênio e fósforo na produção de biomassa em insulina}

A adubação nitrogenada, em conjunto com a fosfatada, influenciou na produção de biomassa em plantas de insulina. Verificou-se coloração amarelada nas folhas e menor desenvolvimento nas plantas mantidas nos tratamentos com baixas concentrações de nitrogênio, quando comparadas com as dos demais tratamentos, provavelmente, devido ao fato do nitrogênio fazer parte da estrutura da clorofila. Uma vez que na ausência deste, não ocorre a formação do pigmento fotossintetizante em quantidade suficiente (Salisbury \& Ross, 1992).

A matéria seca de folhas foi escolhida para explicar a produção de biomassa, neste trabalho, por ser o órgão com maior atividade fotossintética e porque permite representar o ganho de 


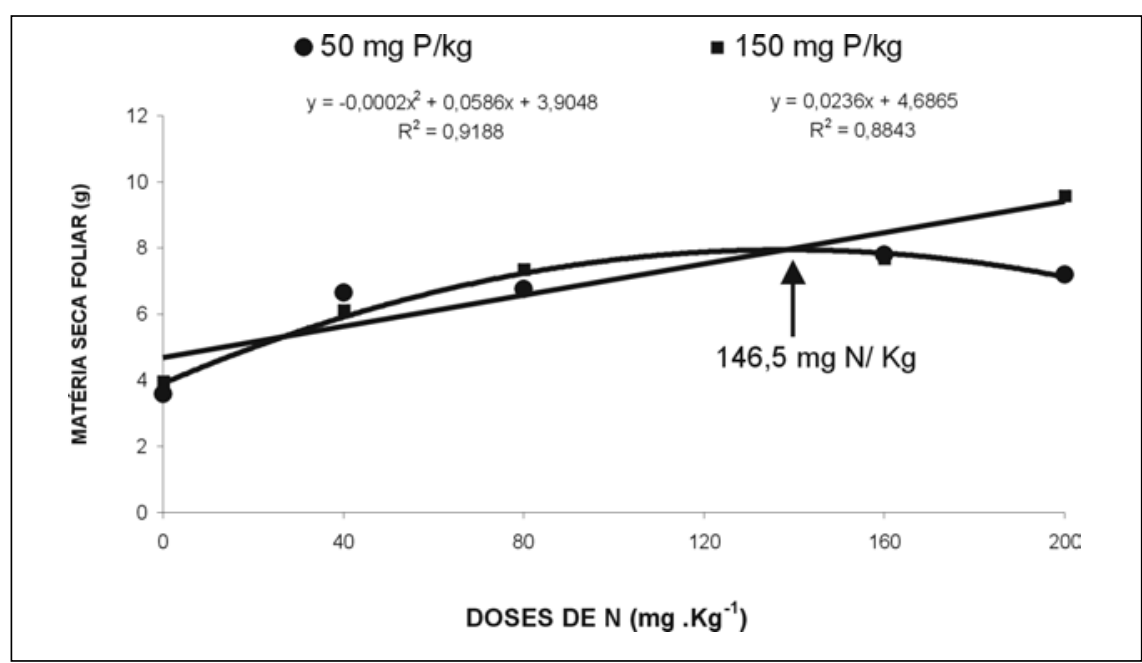

Figura 1. Matéria seca foliar de plantas de insulina, em função da aplicação de diferentes doses de nitrogênio e fósforo. Lavras, UFLA, 1998.

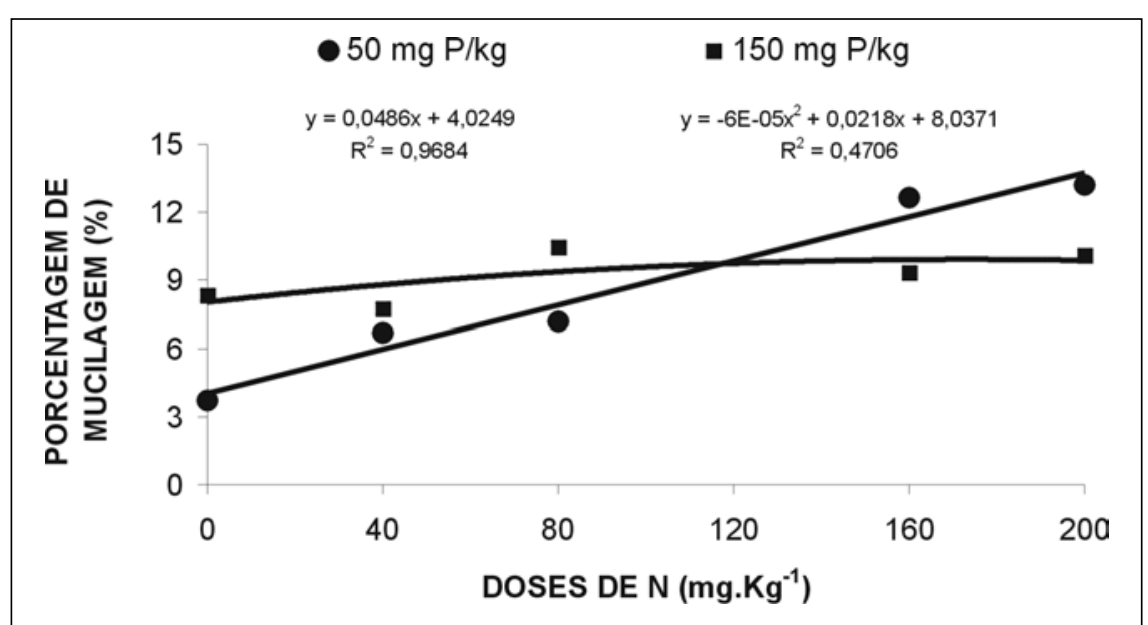

Figura 2. Porcentagem de mucilagem na parte aérea de plantas de insulina, aos 90 dias, submetidas a diferentes doses de nitrogênio e fósforo. Lavras, UFLA, 1998.

matéria seca na planta como um todo. Observou-se interação entre as doses de fósforo e nitrogênio na produção de matéria seca (Figura 1), ocorrendo resposta quadrática para a dose de $50 \mathrm{mg}$ $\mathrm{P} / \mathrm{Kg}$ de nitrogênio e linear para a dose $150 \mathrm{mg} \mathrm{P} / \mathrm{Kg}$ de solo.

A partir das equações de regressão apresentadas na Figura 1, obteve-se a dose de 146,5 mg de nitrogênio no solo, que permitiu a máxima produção de matéria seca foliar quando da aplicação de $50 \mathrm{mg} \mathrm{P} / \mathrm{kg}$ de solo. Para a aplicação de $150 \mathrm{mg} \mathrm{P} / \mathrm{kg}$ de solo não foi possível encontrar a dose que permitiu a máxima produção de matéria seca foliar, uma vez que a resposta, em produção de matéria seca, foi linear. Quando comparou-se as duas doses de fósforo, verificou-se que a maior produção de biomassa foliar ocorreu na dose de 150 $\mathrm{mg} \mathrm{P} / \mathrm{kg}$ nas maiores doses de N. O nitrogênio é utilizado na síntese de proteínas e aminoácidos e, para a conclusão do processo, é necessária a presença de fósforo na forma de poder redutor e de nucleotídeos (Glass, 1989). Portanto, com o aumento na concentração de $\mathrm{N}$, ocorreu a necessidade de elevar a concentração de fósforo para dar início aos processos de síntese. No entanto, na dose de $50 \mathrm{mg} \mathrm{P} / \mathrm{kg}$, o máximo ganho de matéria seca foliar ocorreu com a aplicação de $146 \mathrm{mg} \mathrm{N} / \mathrm{kg}$ de solo, uma vez que a concentração de fósforo foi insuficiente para dar continuidade aos processos fisiológicos. Becker (1997) e Lima Filho (1995) obtiveram ganho de matéria seca total em plantas de Phyllanthus niruri e Stevia rebaudiana, respectivamente, com o aumento crescente nas doses de nitrogênio, onde a dose que proporcionou a máxima produção de biomassa da parte aérea foi de $79,89 \mathrm{mg} \mathrm{N}$ e 74,2 mg N/kg de solo, respectivamente, mostrando que há diferenças no requerimento do nutriente por espécies distintas.

A absorção de enxofre diminuiu à medida que a concentração de nitrogênio aumentou, para as duas doses de fósforo. Este comportamento foi também verificado por Furtini Neto (1988) em espécies de eucalipto submetidas a diferentes concentrações de enxofre, sendo este fato atribuído ao efeito de diluição, causado pela maior produção de matéria seca.

O conteúdo de nutrientes é utilizado para demonstrar o efeito de concentração ou diluição dos elementos nos tecidos das plantas em função da absorção dos nutrientes adicionados no solo e, consequentemente, da produção de matéria seca (Becker, 1997). Aplicando 50 $\mathrm{mg} \mathrm{P} / \mathrm{Kg}$ de solo o maior acúmulo de $\mathrm{N}, \mathrm{P}, \mathrm{K}, \mathrm{Ca}$ e Mg ocorreu com a aplicação de $160 \mathrm{mg} \mathrm{N} / \mathrm{kg}$ de solo. Por outro lado, aplicando $150 \mathrm{mg} \mathrm{P} / \mathrm{kg}$ de solo o maior acúmulo dos macronutrientes $\mathrm{N}$, $\mathrm{P}, \mathrm{K}, \mathrm{S}, \mathrm{Ca}$ e Mg ocorreu com a aplicação de $200 \mathrm{mg} \mathrm{N} / \mathrm{kg}$ de solo (Tabela 2).

Teor de mucilagem na parte aérea de insulina

Verificou-se incremento na produção de mucilagem com o aumento das doses de nitrogênio aplicadas. Combinando a aplicação de $50 \mathrm{mg} \mathrm{P}$ com $200 \mathrm{mg} \mathrm{N} / \mathrm{kg}$ de solo obteve-se o valor máximo de 13,2\% de mucilagem (Figura 2). Combinando a aplicação de 150 $\mathrm{mg} \mathrm{P}$ com $80 \mathrm{mg}$ de N/kg de solo obteve-se $10,5 \%$ de mucilagem como valor máximo. Trabalhos de extração de mucilagem, em plantas de insulina, realizados no Instituto de Botânica do Estado de São Paulo, apresentaram a produção de $1,1 \%$ de mucilagem em relação ao material seco obtido de plantas matrizes mantidas em casa de vegetação, resultado muito inferior aos menores resultados do presente trabalho.

Analisando a curva obtida com a aplicação de $150 \mathrm{mg} \mathrm{P} / \mathrm{kg}$ de solo, verificou-se aumento crescente na porcentagem de mucilagem formada. Contudo, com aplicações acima de 181,7 mg $\mathrm{N} / \mathrm{kg}$ de solo, houve diminuição 
Tabela 1. Teores de macronutrientes por g. $\mathrm{Kg}^{-1}$ na matéria seca foliar de plantas de insulina submetidas a doses de nitrogênio e fósforo. Lavras, UFLA, 1998.

\begin{tabular}{|c|c|c|c|c|c|c|c|}
\hline \multicolumn{2}{|c|}{ Doses (mg.kg $\left.{ }^{-1}\right)$} & $\mathbf{N}$ & $\mathbf{P}$ & $\mathbf{K}^{* *}$ & $\mathbf{S}$ & $\mathrm{Ca}^{* *}$ & $\mathrm{Mg}$ \\
\hline $\mathbf{N}$ & $\mathbf{P}$ & \multicolumn{6}{|c|}{ g. kg $^{-1}$} \\
\hline 0 & 50 & 18,5 & 1,9 & 20,8 & 2,2 & 37,0 & 6,2 \\
\hline 40 & 50 & 27,1 & 2,2 & 21,4 & 1,7 & 35,7 & 6,0 \\
\hline 80 & 50 & 37,5 & 2,6 & 22,5 & 1,6 & 37,7 & 6,0 \\
\hline 160 & 50 & 42,2 & 2,4 & 23,6 & 1,4 & 38,7 & 5,5 \\
\hline 200 & 50 & 39,7 & 2,5 & 23,5 & 1,4 & 39,7 & 5,7 \\
\hline 0 & 150 & 22,5 & 2,0 & 23,0 & 2,4 & 40,5 & 5,7 \\
\hline 40 & 150 & 28,5 & 2,5 & 22,3 & 2,3 & 38,7 & 6,2 \\
\hline 80 & 150 & 36,2 & 2,7 & 23,2 & 1,9 & 39,0 & 6,0 \\
\hline 160 & 150 & 42,4 & 2,9 & 24,0 & 1,6 & 40,2 & 5,2 \\
\hline 200 & 150 & 44,3 & 2,9 & 22,5 & 1,6 & 41,0 & 5,0 \\
\hline
\end{tabular}

** Interação significativa ao nível de 5\% de significância enre $\mathrm{N}$ e P.

Tabela 2. Conteúdo de macronutrientes em mg/vaso na matéria seca foliar de plantas de insulina, submetidas a diferentes doses de nitrogênio e fósforo. Lavras, UFLA, 1998.

\begin{tabular}{cc|cccccc}
\hline \multicolumn{2}{c|}{ Doses $\left(\mathbf{m g}_{\mathbf{~ k g}} \mathbf{- 1}\right)$} & $\mathbf{N}$ & $\mathbf{P}$ & $\mathbf{K}$ & $\mathbf{S}$ & $\mathbf{C a}$ & $\mathbf{M g}$ \\
\hline $\mathbf{N}$ & $\mathbf{P}$ & \multicolumn{7}{c}{$\mathbf{m g} / \mathbf{v a s}$} \\
\hline 0 & 50 & 66,7 & 6,8 & 75,1 & 7,8 & 133,2 & 22,4 \\
40 & 50 & 181,7 & 14,5 & 142,6 & 11,5 & 237,7 & 39,9 \\
80 & 50 & 253,9 & 17,7 & 152,7 & 10,7 & 255,7 & 40,6 \\
160 & 50 & 330,6 & 19,1 & 184,3 & 10,8 & 302,5 & 42,7 \\
200 & 50 & 286,0 & 17,8 & 169,7 & 10,0 & 286,2 & 41,3 \\
0 & 150 & 90,1 & 8,0 & 91,3 & 9,5 & 161,1 & 22,8 \\
40 & 150 & 173,3 & 15,2 & 136,9 & 14,0 & 237,1 & 38,2 \\
80 & 150 & 267,0 & 20,1 & 171,0 & 14,1 & 287,6 & 44,2 \\
160 & 150 & 322,6 & 22,5 & 184,9 & 12,3 & 309,3 & 40,2 \\
200 & 150 & 425,5 & 27,9 & 216,0 & 15,4 & 395,6 & 48,2 \\
\hline
\end{tabular}

gradativa na formação de mucilagem. Tal efeito não ocorreu quando se aplicou $50 \mathrm{mg} \mathrm{P} / \mathrm{kg}$ de solo, verificando-se aumento crescente na produção de mucilagem com o aumento das doses de nitrogênio aplicados, não sendo possível verificar a dose de nitrogênio que permitiu máxima produção de mucilagem, uma vez que a resposta foi linear (Figura 2). Os resultados diferem dos encontrados na literatura, onde a porcentagem de mucilagem extraída de raízes de Glossostemom bruguiri diminuiu de 14,$3 ; 12,9$ para $11,3 \%$, à medida que aumentavam as doses de nitrogênio aplicados $(0 ; 72$ e 108 mg/kg) (ElGengaihi et al., 1995).

As mucilagens produzidas nas raízes e sementes têm função de reserva ou proteção, pois acumulam-se sobre a pa- rede celular de forma semelhante ao acúmulo de amido. Almetov \& Trukhan (1988) afirmam que aumentos nas doses de NPK aumentam a produção de raízes tuberosas em batata doce, mas diminuem o conteúdo de amido nas mesmas. Saghin (1989) relata que aumentos nas doses de nitrogênio e fósforo também diminuíram o conteúdo de amido em batata. Isso se deve ao fato do fósforo, na forma de ortofosfato (Pi), ser o regulador no particionamento da triose fosfato formada no ciclo de Calvin, entre a síntese de amido e a de sacarose. Altas concentrações de fósforo (Pi) no citosol, direcionam a triose fosfato do cloroplasto para o citosol e ocorre a síntese de sacarose, e baixas concentrações de Pi no citosol permitem que a triose fosfato seja direcionada para a síntese de amido no próprio cloroplasto (Taiz \& Zaiger, 1998). Conclui-se que o menor conteúdo de amido, nestes casos, pode ser decorrente do maior ganho de matéria seca da parte aérea.

Mucilagens produzidas nos órgãos aéreos são os polissacarídeos presentes na estrutura da parede celular, portanto, qualquer fator que influencie na síntese e elongação da parede irá também influenciar numa maior produção de polissacarídeos de parede. A parede celular é um sistema altamente complexo e dinâmico, cuja composição e estrutura variam durante o crescimento e a diferenciação da célula em resposta a fatores do ambiente. As paredes primária e secundária diferem química e fisicamente, ambas constituídas por polissacarídeos, glicoproteínas, água e 
Tabela 3. Conteúdo de mucilagem na parte aérea de plantas de insulina, aos 90 dias, submetidas a diferentes doses de nitrogênio e fósforo. Lavras, UFLA, 1998.

\begin{tabular}{|c|c|c|c|c|c|c|c|c|c|c|}
\hline & \multicolumn{10}{|c|}{ Doses de N (mg.kg $\left.{ }^{-1}\right)$} \\
\hline & 0 & 40 & 80 & 160 & 200 & 0 & 40 & 80 & 160 & 200 \\
\hline & \multicolumn{5}{|c|}{50 mg P. kg $^{-1}$} & \multicolumn{5}{|c|}{150 mg P. kg $^{-1}$} \\
\hline MSPA $(g)$ & 12,1 & 17,8 & 13,6 & 16,8 & 14,2 & 16,1 & 17,7 & 19,0 & 16,8 & 21,3 \\
\hline Mucilagem (\%) & 3,7 & 6,7 & 7,2 & 12,6 & 13,2 & 8,3 & 7,7 & 10,5 & 9,3 & 10,1 \\
\hline CMPA (g/vaso) & 0,4 & 1,2 & 1,0 & 2,1 & 1,9 & 1,3 & 1,4 & 2,0 & 1,6 & 2,1 \\
\hline
\end{tabular}

MSPA = matéria seca da parte aérea

CMPA = conteúdo de mucilagem da parte aérea

compostos fenólicos em diferentes proporções (Braga, 1994). Os carboidratos, presentes na forma de polissacarídeos, são os componentes mais importantes da parede celular, representando $90 \%$ da mesma nos tecidos em crescimento, estando entre os mais complexos encontrados no reino vegetal (Brett \& Waldron, 1983).

A partir da mucilagem extraída de plantas matrizes de insulina, foi possível determinar a composição química da mesma, onde foram encontrados: $6,5 \%$ de açúcar total, $1,7 \%$ de açúcar redutor, $6,7 \%$ de ácido urônico e $0,4 \%$ de proteínas solúveis. De acordo com Costa (1978) as mucilagens são polissacarídeos ácidos, compostas por vários monossacarídeos ligados ao ácido urônico. Portanto, os polissacarídeos extraídos, no presente trabalho podem ser classificados como mucilagens.

As maiores produções de mucilagem (12,6 e 13,2\%) ocorreram nos tratamentos em que houveram os menores valores de matéria seca foliar, ou seja nas aplicações de $50 \mathrm{mg} \mathrm{P} / \mathrm{kg}$ de solo combinados com as maiores concentrações de nitrogênio (Tabela 3). Quando se considera o conteúdo de mucilagem $(\mathrm{mg} /$ por vaso), verifica-se que o maior acúmulo deste polissacarídeo ocorreu nas maiores concentrações de nitrogênio, na maior concentração de fósforo. Portanto, a espécie é responsiva à adubação nitrogenada e fosfatada, sendo justificada a sua recomendação visando uma maior produção de biomassa e de mucilagem.

\section{AGRADECIMENTOS}

Os autores agradecem à FAPEMIG e FINEP pelo financiamento deste trabalho.

\section{LITERATURA CITADA}

ALBUQUERQUE, J.M.D. Plantas medicinais de uso popular. Brasília: ABEAS,. (Programa de agricultura nos Trópicos, 6), 1989. $96 \mathrm{p}$.

ALMETOV, N.S.; TRUKHAN, L.G. Effect of mineral fertilizer on yield and quality of potatos in Mariayaka. Agrokimiya. v. 3, p. 45-46, 1988. BECKER, L. Propagação vegetativa in vivo e in vitro, indução de calos, nutrição, extração e quantificação de alcalóides nas espécies Phyllanthus niruri l. e Phyllanthus corcovadensis muell. Arg. (Quebra-Pedras). Lavras:UFLA, 1997. 96 p (Tese mestrado).

BRAGA, M.R. Oligossacarinas indutores de fitoalexinas obtidas de paredes celulares de rubiáceas nativas. São Paulo: USP, 1994. 150 p (Tese doutorado)

BRETT, C.; WALDRON, K. Physiology and biochemistry of plant cell walls In: Topics in Plant Physiology, New york: Academic Press,1983. p. 234-257.

CAMARGO, O.A; MONIZ, A.C.; JORGE, J.A.; VALADARES, J.M.A.S. Métodos de análise química, mineralógica e fisica de solos do Instituto Agronomico de Campinas. Campinas: IAC, 1986.94 p.

COSTA, C.M.M. Cipó-pucá (Cissus sycioides). Rio de janeiro, Apostila do curso de Especialização em Medicamentos da UFRJ, 1990. 109 p.

COSTA, A.F.(ed.) Substâncias Poliurônicas. In: Farmacognosia. Lisboa, Fundação Calouste Gulbenkian, 1978. v. 2, p. 84-125.

CLEMENTE FILHA, A.C. Aspectos fisiológicos e fitoquímicos de Bauhinia forficata Link e Plantago major L. Lavras: UFLA, 1996. 82 p.(Tese mestrado)

EL-GENGAIHI, S.; TURKEY, K.A.; SHALABY, A.S.; IBRAHIM, N.A. Effect of fertilization treatments on yield parameters and mucilage and fat contents in roots of Moghat (Glossostemon bruguiri Desf.). Plant Foods for Human Nutrition. v. 47, p. 239-244, 1995.

ELIZABETSKY, E. Ação anticonvulsivante de Cissus sycioides, cipó-pucá. Ciência e Cultura. v. 40, n. 7 supl., p. 985 (resumo), 1988.

EMBRAPA - Serviço Nacional de Levantamento e Conservação do Solo. Manual de métodos de análise do solo. Rio de Janeiro, 1979. 86 p.

FURTINI NETO, A.E. Efeito do enxofre no crescimento e assimilação de nitrogênio por diferentes espécies de eucalipto. Lavras: UFLA, 1988. 95 p. (Tese mestrado)

GLASS, A.D.M. Plant Nutrition. In: JONES, L. 7 BERTLETT, A. (eds.) An Introduction to Current Concepts. Boston: Academic Press, 1989. p. 234-254
LIMA FILHO, O.F. Distúrbios nutricionais, marcha de absorção de nutrientes, análise do crescimento e teor de esteviosídeos em Estévia (Stevia rebaudiana (Bert.) Bertoni). Piracicaba: ESALQ, 1995. 212 p (Tese doutorado)

MARSCHNER, H. Mineral Nutrition of Higher Plants. 2.ed. New York: Academic Press 1995. p. 889-901.

MOORBY, J.; BESFORD, R.T. Mineral Nutrition and Growth. In: Encyclopedia of Plant Physiology - Inorganic Plant Nutrition. Spring - Verlag: New york, 1983. p. 481-521.

MOURA, B.A.S. Estudo químico e farmacológico de espécie vegetal Cissus sycioides Linn. (Apostila do curso de especialização em química de produtos naturais da Universidade do Pará), Belém, 1986. p. 98.

PEPATO, M.T; KELLER, E.H; SILVA, M.P.M; BAVIERA, A.M. Efeito da administração crônica de Cissus sicyoides no metabolismo de carboidratos. In: SIMPÓSIO BRASILEIRO DE PLANTAS MEDICINAIS, Águas de Lindóia, 1998. p. 78. ROBSON, A.D.; PITMANN, M.G. Interactions between nutrients in Higher Plants. In: LAUCHLI, A.; BIELESKI, R.L.(eds.) Inorganic Plant Nutrition. Berlin: Spring - Verlag, 1983. p. 147-180.

SAGHIN, G. Effect of organic and mineral fertilizers on potato yield in the mountain zone of Suceova country. Cercetari Agronomice in Moldova. v. 22, n. 2, p. 71-74, 1989.

SALISBURY, F.; ROSS, C.W. Plant Physiology. California: Wadsworth, 1992. 682 p.

SIERAKOWSKI, M.R. Alguns aspectos quimicos, fisico-químicos e estruturais da mucilagem extraida de folhas de Pereskia aculeata. Curitiba: UFPA, 1982. 92 p. (Tese doutorado)

SILVA, M.C.P. Biomassa e mucilagem de Tanchagem (Plantago major L.) em função das adubações orgânica, mineral e mista e da supressão das inflorescências. Botucatu: UNESP, 1995. 72 p. (Tese mestrado)

SILVA, G.A. Caracterização e padronização farmacológica da droga e extrato fluído de Cissus sycioides L. São Paulo: Universidade Estadual de São Paulo, 1995. 82 p. (Tese mestrado)

TAIZ, L.; ZAIGER, E. Plant Physiology. 2. ed. Los Angeles: The benjamim/CuMnings, 1998. 559 p. TOLEDO, M.C.F. Anthocyanins from anil trepador (Cissus sycioides). Journal Food Science, v. 48, p. $1368-1369,1983$.

TOMODA, M.; SHIMIZU, N.; OSHIMA, Y.; TAKAHASHI, M.; MURAKAMI, M.; HIKINO,

H. Hypoglicemic activity of twenty plant mucilages and three modified products. Planta Medica. v. 20, p. 8-12, 1987.

VETTORI, L. Métodos de análise de solo. Rio de Janeiro: Ministério da Agricultura, 24 p. (Boletim Técnico, 7), 1969. 